\title{
Contextual diversity in telephone interpreting: Voices from healthcare interpreters in Scotland
}

\author{
Claudia V. Angelelli \\ Heriot-Watt University, Edinburgh \\ c.angelelli@hw.ac.uk \\ https://orcid.org/0000-0002-8452-4754 \\ Jonathan Maurice Ross \\ Boğaziçi University, Istanbul \\ jonathan.ross@boun.edu.tr \\ https://orcid.org/0000-0002-2537-8582
}

\begin{abstract}
This study conducted in Scotland focuses on the contextual factors that shape healthcare interpreters' performance when they interpret over the telephone. It draws on the findings of two focus groups ( $n=5$ and 7) conducted in a Scottish urban area in 2017 among healthcare interpreters with experience in telephone interpreting (TI). The participants shared their experiences in $\mathrm{TI}$ as they related to issues that include (1) the impact of different equipment used by interpreters and clients respectively and (2) the interpreting strategies and techniques deployed in TI. Another issue that emerged from the focus groups was work-life balance. Judging by their contributions, healthcare interpreters are influenced by a multitude of factors when they interpret over the telephone, some of which have been accorded sufficient significance in the literature. Among the less-discussed factors are the specific kind of equipment used by healthcare providers and the policy of the interpreter's employer regarding the use of mobile phones. The participants' input suggests that they respond to the challenges of $\mathrm{TI}$ linked to the use of certain technologies with assertiveness and creativity, although they may not be fully aware of the consequences of some of their behaviours. This article highlights the value of focus groups in exploring diversity in a situated practice.
\end{abstract}

Keywords: telephone interpreting; healthcare interpreting; remote interpreting; interpreting technology; contextual diversity

\section{Introduction}

Whereas telephone interpreting (TI) began in Australia in 1973 and made inroads into England in the early 1990s (Mikkelson, 2003), it was not until the following decade that it started establishing itself in Scotland. While this occurred in pre-COVID-19 times, the current pandemic has precipitated a marked increase in the use of remote interpreting of various types, among them TI (Houria, 2021; Nimdzi Research, 2020; René de Cotret et al., 2020). Research on the use of this mode in Scotland, however, has not been conducted and neither 
Angelelli, C. V., \& Ross, J. M. (2021). Contextual diversity in telephone interpreting: Voices from healthcare interpreters in Scotland. Linguistica Antverpiensia, New Series: Themes in Translation Studies, 20, 74-93.

have Scottish telephone interpreters' experiences been explored. In 2017, the co-authors conducted a study in an urban area of Scotland, Thistleshire, ${ }^{1}$ to elicit healthcare interpreters' perceptions of and opinions on providing TI in healthcare settings. Two focus groups $(n=5$ and 7) of Thistleshire region-based healthcare interpreters with $\mathrm{Tl}$ experience provided the data. The present article analyses and discusses the results of these focus groups.

While TI has been growing exponentially, the growth in business has exceeded that in research (Braun, 2015). This article contributes to the body of literature on TI by deploying focus groups to explore this particular situated practice. Focus groups can uncover the different experiences and perspectives of interpreters with respect to TI. Such differences may reveal important details reflecting the preferences of individual interpreters and the role of the organisations in which they work, as well as the complexities of $\mathrm{Tl}$ as a situated practice. All of these contextual variables have an impact on both interpreters' professionalism and their interpreting quality.

After a brief review of the relevant literature, including works about $\mathrm{Tl}$ in Scotland to delineate the specific context in which TI occurs, the article explores the interconnected themes of technology and interpreters' strategies and procedures. It then discusses the results of our study conducted using focus groups. Our goal is to tease out the challenges participants face when trying to balance their professional mandate with the realities of this specific situated practice. Although the focus groups covered a number of themes suggested by a review of the existing literature on $\mathrm{TI}$ (see the semi-structured protocol in Appendix A), this study reports on only two topics, namely, the specific kinds of telephone and communicative configuration involved in the interpreted event and the impact that these have on telephone interpreters' behaviours.

\section{Telephone interpreting in healthcare: brief review of relevant literature}

The existing empirical research on $\mathrm{TI}$, which can also illuminate its application in healthcare, consists largely of analyses of interpreted calls aimed at identifying patterns in interpreter behaviour. This is achieved by comparing interpreted with non-interpreted telephone calls (Oviatt \& Cohen, 1992) or interactions interpreted face-to-face (F2F) with those interpreted via telephone (Angelelli, 2004; Wadensjö, 1999) or by conducting analyses of larger data sets of telephone-interpreted discourse (Amato, 2018; Rosenberg, 2007). In addition, researchers use methods such as surveys and interviews to elicit telephone interpreters' perspectives on their work (Cheng, 2015; Lee, 2007; Wang, 2018a, 2018b), which provide fruitful insights into working conditions and practices. This information is vital to understanding diversity in TI, which may be related to variables such as the types of telephone used, the different settings in which Tl is observed, the backgrounds of interpreters and the policies and attitudes of those who employ them or rely on their services.

In addition to literature reviews (Ozolins, 2011), non-empirical writings on TI include expositions of the advantages and disadvantages of TI (Braun, 2015; Gracia-García, 2002) and material providing guidance for practice and training (Amato et al., 2018). 
Angelelli, C. V., \& Ross, J. M. (2021). Contextual diversity in telephone interpreting: Voices from healthcare interpreters in Scotland. Linguistica Antverpiensia, New Series: Themes in Translation Studies, 20, 74-93.

\subsection{Studies on services, clients and interpreters}

A number of medical studies (e.g., Azarmina \& Wallace, 2005; Gany et al., 2007; Hornberger et al., 1996, 1997; Joseph et al., 2018; Lion et al., 2015) have investigated TI from the end users' perspectives, that is, those of healthcare institutions, healthcare professionals and patients. Other studies compare healthcare interpreters' satisfaction with different modes of interpreting, for example, F2F, TI or video interpreting (VI) (Locatis et al., 2010; Price et al., 2012). At least one experiment suggests that $\mathrm{TI}$ does not adversely affect the quality of the information transfer but it does increase problems with interaction (De Boe, 2019, 2020). In the studies that focus on telephone healthcare interpreting there is a noticeable absence of interpreters' reflections on the strategies and methods they deploy. In Angelelli's ethnographic study at California Hope (2004), 95 per cent of the 392 interactions studied were interpreted over a speakerphone. While the focus is not on $\mathrm{TI}$, this study still offers evidence of interpreters' behaviours, perceptions and attitudes, reflecting on their performance both remotely and F2F. Our study contributes to the literature on $\mathrm{TI}$ by using focus groups to explore healthcare interpreters' perspectives on their work over the telephone, examining the connection between their performance and the technology used by interpreters, organisations and their clients.

\subsection{Studies on discourse on TI}

Whether they are based on experiment (e.g., De Boe, 2019; Oviatt \& Cohen, 1992), naturalistic observation (e.g., Angelelli, 2004; Castagnoli \& Niemants, 2018; Wadensjö, 1999) or the testimony of interpreters (Cheng, 2015; Lee, 2007; Wang, 2018a, 2018b), most of the studies concerned with the ways in which telephone interpreters work emphasise their role as interventionist communication managers. Telephone interpreters do far more than simply "translate" messages: they coordinate others' talk both implicitly and explicitly (Wadensjö, 1999), which is not unique to TI (see Baraldi \& Gavioli, 2012). Discourse-based studies of TI suggest that telephone interpreters, conscious of the threat that factors such as the lack of visual contact and poor audibility pose to effective communication, compensate for these in verbal ways. For instance, they repeat their own utterances, request the other parties to confirm what they have said or indicate explicitly whose turn it is to talk (Oviatt \& Cohen, 1992). In her comparative study of TI, VI and F2F, De Boe $(2019,2020)$ observed a marked difference in the extent to which remote interpreters and $F 2 F$ interpreters intervene in a conversation to optimise communication between providers and clients.

While studies generally present telephone interpreters as proactive coordinators, there is less uniformity regarding the linguistic forms interpreters use to render interlocutors' utterances. Participants trained in interpreting are familiar with the tacit rule about using the first-person pronoun and avoiding the third person and indirect speech (Cheng, 2015; Wang, 2018b). However, whereas some abide by this rule, others are more pragmatic. For instance, NAATIaccredited telephone interpreters who were surveyed reported resorting to the third person to clarify whose perspective they were representing while using the first person to assert their own agency as the coordinator of communication (Lee, 2007).

Like F2F interpreters, telephone interpreters, whenever feasible, offer a brief pre-session to explain their role to the interlocutors and set some ground rules. In Xu et al.'s observational 
Angelelli, C. V., \& Ross, J. M. (2021). Contextual diversity in telephone interpreting: Voices from healthcare interpreters in Scotland. Linguistica Antverpiensia, New Series: Themes in Translation Studies, 20, 74-93.

study of TI for a Legal Aid Commission in Australia (2020), the apparent lack of a briefing in most of the interactions studied is seen as evidence of interpreters' insufficient professionalism. Other studies report how, when providers are pushed for time, interpreters (both professional and non-professional) may be cut off and briefings cannot take place (Angelelli, 2004).

Interpreted telephone interactions commonly comprise sequences of monolingual "extended sub-dialogues" (Oviatt \& Cohen, 1992, p. 11) between the interpreter and each of the primary interlocutors (cf. Rosenberg, 2007; Ross, 2019). Data show that long side conversations are a fact in TI (Angelelli, 2011; Castagnoli \& Niemants, 2018) and that they can fulfil a valuable function of creating common ground among all the parties, even if they are strongly discouraged in non-empirically based standards of practice and training.

\subsection{Communicative configurations, technology and TI practice}

Problematising a monolithic concept of "telephone interpreting" in an analysis of his own work experience as a telephone interpreter, Rosenberg (2007) differentiates between three configurations:

- three-way calls, where all the parties are using separate phones;

- remotely interpreted calls where the client and the public service provider use a speakerphone ("speakerphone interpreting"); and

- remotely interpreted calls in which the client and the public service provider share a single hand-set ("phone passing").

Rosenberg (2007) associates extended sub-dialogues with calls involving phone passing, described as "two parallel conversations in which the interpreter is being used as an emissary" (p. 73). He recalls using only third-person forms when interpreting for phone passing and doing the same in $82-85 \%$ of the other kinds of calls. As is the case with all self-reflective studies, Rosenberg's findings represent his practice alone. However, even if some of the interpreting behaviours he discussed (e.g. use of third person) might be seen as controversial, his distinction between sub-modes of TI offers a nuanced approach to $\mathrm{TI}$ practice. This deconstruction of TI has been echoed by others (Ross, 2019; Spinolo, 2018; Spinolo et al., 2018), but its validity needs to be tested using primary data involving a larger number of interpreters.

Another variable not sufficiently studied is the technology used by interpreters, which is part and parcel of their working context. It is likely to make a difference whether the interpreter is using a landline, a mobile telephone or a mobile application and is connected to the call through a conventional receiver, a loudspeaker, an operator's headset or a Bluetooth connection (Cheng, 2015). When interpreters, for example, do not use headphones or a headset and have to hold their phones, this makes note-taking more difficult $(K o, 2006)$.

Although some $\mathrm{TI}$ service providers and professional associations advise against the use of mobile phones because of potentially bad reception, poor sound quality (Lee, 2007), focus, confidentiality issues and the extra cost to the provider, a few studies indicate that interpreters are increasingly using mobile phones for their TI work (Cheng, 2015). This issue 
Angelelli, C. V., \& Ross, J. M. (2021). Contextual diversity in telephone interpreting: Voices from healthcare interpreters in Scotland. Linguistica Antverpiensia, New Series: Themes in Translation Studies, 20, 74-93.

triggered our curiosity, as little research has been done on the impact that interpreters' use of certain technologies has on their working-patterns and performance. The use of mobile phones and other technologies also sheds light on the relationship between interpreters' practice and TI providers' policies.

\subsection{Public service interpreting and telephone interpreting in Scotland}

Research related to TI in Scotland is scant. In 2004, the first comprehensive review of language service provision in the country found that there were no Scotland-based TI providers (Perez \& Wilson, 2006). The country's TI needs were met by companies headquartered elsewhere, although some of the interpreters were located in Scotland. As with Perez and Wilson's study, subsequent research related to $\mathrm{TI}$ in Scotland has mostly handled the subject from the perspective of parties other than interpreters (McKelvey, 2019; Monteoliva-García, 2020). Nonetheless, together with official documents (see McKelvey, 2019), these studies can illuminate the concrete circumstances within which healthcare interpreters in the Thistleshire region provide interpreting services over the telephone.

In Thistleshire, as in the other NHS regions of Scotland, TI has been provided largely by the commercial agency or agencies winning a tender. Although the TI provider and its employees are contractually bound to conform to standards set by the NHS, the regional health board has limited opportunity to influence recruitment and regulate the enforcement of standards. Therefore, the quality of the TI provided by interpreters depends on their skills and knowledge and on the (pre- or in-service) training provided by agencies.

Secondly, an issue emerging from the literature is the neglect of $\mathrm{Tl}$ in conventional training programmes in the United Kingdom, Scotland included. Telephone and video-conference interpreting are only optional components in the training and assessment of public service interpreters (De Pedro Ricoy, 2010), although, more recently, course components have emerged at universities in England and Scotland. The Diploma in Public Service Interpreting (DPSI), which members of NHS Lothian's F2F staff bank are expected to possess (McKelvey, 2019), does not test candidates' performance as telephone interpreters.

Thirdly, the user-oriented literature on $\mathrm{TI}$ is also revealing. Health service providers' and clients' experiences can help to contextualise the practice of the remote interpreter. For example, an impact assessment report about the transfer of the NHS Interpreting and Translation Service from Edinburgh Council to NHS Lothian in June 2017 notes that $\mathrm{TI}$ is especially problematic for health practitioners "where the necessary equipment is not available" (Mitchell, 2018). This observation hints at the impact that technological deficiencies can have on the work of interpreters, a point that emerged strongly in our focus groups. Although such depictions of the way end-users experience $\mathrm{Tl}$ in Scotland do occur in the literature, the viewpoints of interpreters remain an untapped source.

In sum, a thorough review of the literature on $\mathrm{TI}$ and on healthcare interpreting in particular highlights the following topics: 
Angelelli, C. V., \& Ross, J. M. (2021). Contextual diversity in telephone interpreting: Voices from healthcare interpreters in Scotland. Linguistica Antverpiensia, New Series: Themes in Translation Studies, 20, 74-93.

1. Telephone technologies and communicative configurations in $\mathrm{TI}$

2. Interpreters' strategies and procedures in $\mathrm{TI}$

3. The affective dimension of $\mathrm{TI}$ for the interpreter (including stress)

4. The impact on the interpreter of the lack of visual contact.

Topics 3 and 4 have already been discussed sufficiently in the literature, so we did not expect our focus groups to introduce novel or surprising material. Our expectations proved to be reasonable. Topics 1 and 2, however, had rarely been dealt with in the particular context of healthcare interpreting, so we decided to concentrate on them in this article and in this literature review.

\section{Study and method}

The data informing this study come from two focus groups held in Thistleshire in 2017. The data were fully transcribed and the transcriptions examined for inter-rater reliability. To protect the identity of the participants, we used a code such as A1 or B6. The letter " $A$ " refers to the focus group conducted in February 2017 and "B" to that in June 2017. The numbers were those assigned to the participants at the beginning of their respective focus groups.

Focus groups are an efficient method of collecting qualitative data on a subject about which little is known (Edmunds, 1999); they are also a valuable mechanism for asking participants to comment on and suggest explanations for existing research findings. This method can generate a discussion among a small group of individuals selected because they have some knowledge about a particular research question or topic (Böser, 2016; Goebert \& Rosenthal, 2001; Morgan, 1997). In addition, focus groups have occasionally been used in researching interpreting (e.g., Angelelli, 2006; Hild, 2014; Shaw et al., 2004).

\subsection{Procedures}

Once ethical clearance was obtained, interpreters were recruited from local interpreting agencies, NHS Thistleshire's interpreter bank and two well-known online forums for translators and interpreters. The requirement for participation was to have had experience in both $\mathrm{F} 2 \mathrm{~F}$ and $\mathrm{TI}$ in health or health-related settings (see Table 1: Participants' information).

Invitations to participate, including a brief description of the study, were sent via email. The focus groups, facilitated and observed by both co-authors, were audio recorded. Each focus group lasted approximately two hours. Group A gathered in a meeting room in an interpreting agency, Group B in a room at the headquarters of NHS Thistleshire's interpreting service.

The facilitator started the recording and opened the session by thanking the participants for their time and explaining that (1) the participants should preface all their comments by saying the number they had been assigned; (2) they should speak only one at a time when the facilitator gave them the floor; (3) they should avoid monopolizing the conversation. In addition, the facilitator requested interpreters not to engage in side-conversations. The discussion started and the participants were asked to respond to some questions, following a semi-structured protocol that drew on themes emerging from the review of the literature on TI (see Appendix A). 
Angelelli, C. V., \& Ross, J. M. (2021). Contextual diversity in telephone interpreting: Voices from healthcare interpreters in Scotland. Linguistica Antverpiensia, New Series: Themes in Translation Studies, 20, 74-93.

\subsection{Participants}

A total of 12 interpreters participated in this study: 11 female and one male. Table 1 below indicates the languages represented, years of experience and frequency of work per week per group.

As for employment status, nine participants are freelancers and three are full-time interpreters in public institutions such as NHS Thistleshire and local councils.

Regarding education and training, six participants possess the UK's Diploma in Public Service Interpreting, four hold an undergraduate degree in translation and interpreting, five a degree in another language-related field and two an MA/MSc in translation and/or interpreting. Only one participant has had no extensive training in interpreting but has attended several short courses.

Table 1: Participants' information

\begin{tabular}{|c|c|c|c|c|c|c|}
\hline Group & $\begin{array}{c}\text { No. of } \\
\text { partici- } \\
\text { pants }\end{array}$ & $\begin{array}{l}\text { Languages } \\
\text { represented } \\
\text { (other than } \\
\text { English) }\end{array}$ & $\begin{array}{c}\text { Years of } \\
\text { experience in } \\
\mathrm{TI}\end{array}$ & $\begin{array}{c}\text { Years of } \\
\text { experience in } \\
\text { F2F }\end{array}$ & $\begin{array}{c}\text { Weekly hours } \\
\text { of } \mathrm{TI}\end{array}$ & $\begin{array}{l}\text { Weekly hours } \\
\text { of F2F }\end{array}$ \\
\hline $\begin{array}{l}\text { A (02- } \\
2017)\end{array}$ & 5 & $\begin{array}{l}\text { Albanian, } \\
\text { German, } \\
\text { Mandarin, } \\
\text { Polish, } \\
\text { Russian }\end{array}$ & $\begin{array}{l}\text { Mean }=9.8 \\
\text { (range = 2.5- } \\
20)\end{array}$ & $\begin{array}{l}\text { Mean }=10.5 \\
\text { (range }=0.5- \\
26)\end{array}$ & $\begin{array}{l}\text { Mean }=3.2 \\
\text { (range }=1-7)\end{array}$ & $\begin{array}{l}\text { Mean = 17 } \\
\text { (range = 5- } \\
32.5 \text { ) }\end{array}$ \\
\hline $\begin{array}{l}B \\
(06- \\
2017)\end{array}$ & 7 & $\begin{array}{l}\text { Arabic, } \\
\text { French, } \\
\text { Italian, Polish, } \\
\text { Turkish }\end{array}$ & $\begin{array}{l}\text { Mean }=5 \\
\text { (range }=2-10)\end{array}$ & $\begin{array}{l}\text { Mean }=7.5 \\
\text { (range }=4-13 \text { ) }\end{array}$ & $\begin{array}{l}\text { Mean }=1.2 \\
\text { (range }=0-2 \text { ) }\end{array}$ & $\begin{array}{l}\text { Mean }=16.8 \\
(\text { range }=1-30)\end{array}$ \\
\hline TOTAL & 12 & $\begin{array}{l}\text { Albanian, } \\
\text { Arabic, } \\
\text { French, } \\
\text { German, } \\
\text { Italian, } \\
\text { Mandarin, } \\
\text { Polish, } \\
\text { Russian, } \\
\text { Turkish }\end{array}$ & $\begin{array}{l}\text { Mean }=6.6 \\
\text { (range }=2-20)\end{array}$ & $\begin{array}{l}\text { Mean }=7.9 \\
\text { (range = 0.5- } \\
26)\end{array}$ & $\begin{array}{l}\text { Mean }=1.9 \\
\text { (range }=0-7)\end{array}$ & $\begin{array}{l}\text { Mean = } 16.9 \\
\text { (range = 1- } \\
32.5 \text { ) }\end{array}$ \\
\hline
\end{tabular}

Note: All of the participants in Group B, and all but one of those in Group A, were practising healthcare interpreters who, whether full-time or part-time, had provided TI for NHS Thistleshire.

\section{Analysis and findings}

The findings concerning affective dimensions and the lack of visual cues align with those reported in the literature. We also present work-life balance, a topic which surfaced in both 
Angelelli, C. V., \& Ross, J. M. (2021). Contextual diversity in telephone interpreting: Voices from healthcare interpreters in Scotland. Linguistica Antverpiensia, New Series: Themes in Translation Studies, 20, 74-93.

group discussions and which was found to be strongly related to professionalism (or lack thereof) and interpreters' use of mobile phones.

\subsection{Telephone technologies and communicative configurations}

\subsubsection{Telephones used by interpreters}

When interpreters were asked about employers' requirements concerning the type of telephone they could use when providing $\mathrm{TI}$, the following emerged:

- The major UK-wide commercial agencies, with whom at least two interpreters were registered, insist that their interpreters use a landline (A1; $A 5)$;

- Public agencies expect interpreters to be accessible via two numbers, one a landline number, the other a mobile number (B1);

- Local or Scotland-based commercial interpreting agencies allow interpreters to use any kind of phone. Interpreters simply supply these agencies with their mobile phone numbers.

The participants agreed that certain agencies are right to insist that interpreters use landline telephones; however, most still choose to work mainly with a mobile phone. Several explained that their main source of employment and income is F2F and using a mobile allows them to supplement on-site tasks with TI work. Sometimes they take calls between F2F appointments (A5). At short notice, agencies may request interpreters to initiate a call; if they are away from home, they can do so using a mobile phone (B2). While using mobile phones in such ways may bring practical benefits to interpreters and TI providers, it carries potential costs and risks such as a breach of confidentiality, sound clarity, connection quality, focus and interpreter performance (e.g., the difficulty of note-taking while holding a phone, or not finding a quiet spot). The issues involved in using mobile phones are discussed later in relation to nonprofessionalism. From the data it appears that agencies leave the door open for inappropriate practices when they allow this, even though unsuitable practices are easily specified in protocols and training.

\subsubsection{Communicative configurations at the clients' end}

Th participants mentioned that the Scottish GPs' surgeries and hospitals in which they work as on-site interpreters rely on old-fashioned telephone technology instead of the dualhandset phones that are commonly recommended for interpreted calls. None of the participants recalled interpreting on a conference call for the NHS. In 2017, two communicative configurations were observed: speakerphone interpreting and phone passing with a traditional or a mobile telephone.

The participants emphasised the downsides of both configurations. The speakerphone's microphone picks up all the noise in the vicinity, making it more difficult for the interpreter to listen to the primary interlocutors. When a low-quality speakerphone is used, the interpreters may hear the echo of what has been said, increasing the difficulty of providing a complete rendition. Another problem is the distance of the speakerphone from the parties using it. As one respondent stated: 
Angelelli, C. V., \& Ross, J. M. (2021). Contextual diversity in telephone interpreting: Voices from healthcare interpreters in Scotland. Linguistica Antverpiensia, New Series: Themes in Translation Studies, 20, 74-93.

Very often they will also use a loudspeaker [sic] which in theory should make it easier but practically is not helping that much. Because usually the doctor is right next to the loudspeaker and the patient is like metres away. And you can't hear properly what they're saying and you have to ask for repetition. (B3)

In addition, doctors get up from the desk and move away from the microphone to check patients' blood pressure, for example. When this happens, the interpreter can miss part of what the doctor has said (B5). Because of the poor sound quality in speakerphone calls, doctors often give up on them and resort to telephone passing ( $\mathrm{A} 1$ and $\mathrm{A} 5$ ).

This shift, however, or using telephone passing from the outset, does not make the job of the interpreter easier. A participant referred to one of the challenges involved in this particular communicative configuration, saying:

You don't know how quickly that telephone is being passed over, so you don't know who's got the telephone, so you are waiting for some sort of signal from the other end to make sure that the appropriate person has the telephone. (B5)

\subsection{Interpreters' strategies and techniques}

In both focus groups, the participants described what they do when they perform TI. Their comments cover coordinating, managing and coping. As we will see below, the comments suggest interpreters' awareness of their increased responsibility for these activities when using $\mathrm{TI}$ compared to F2F. As a result of this perceived increased responsibility, interpreters need to be more assertive and interventionist to compensate for the lack of visual input and the variability in the audio input:

I find that [...] we tend to check more who's talking to whom, about what [...],'cause when you're face-to-face it's [obvious] what you're talking about, while when you're on the phone it can be a bit, what are they actually talking about now? [...], you need to basically check this kind of things and say [...] "Okay, the interpreter speaking here," and then other things like this. (B4)

In addition to coordinating, 10 out of the 12 participants discussed their insistence on briefing both parties at the beginning of the call. They use this not only to explain their role but also to advise the parties on how to avoid problems such as overlapping or uninterrupted talk and how they will clarify who is next to speak. The participants provided examples of how they use the briefing to "help" clients. In A1's words:

[I]n [...] the nicest voice possible, [you] encourage the person not to be [...] afraid and to speak. And then [you] also ask [the patient] to speak clearly what [...] he has to say [...]. If it is like, through the loudspeakers [sic], [...] as close to the loudspeakers as close as possible, just to make sure that we can hear something.

B5 reports using the briefing to direct the healthcare provider about how she thinks the conversation should be structured, depending on the particular kind of technology used:

Other times, the doctor will straight away [say]: "I've got so and so with me, can you ask what's wrong with her?" Straight away, without saying anything, you know. And then I will say, "Is it a 
Angelelli, C. V., \& Ross, J. M. (2021). Contextual diversity in telephone interpreting: Voices from healthcare interpreters in Scotland. Linguistica Antverpiensia, New Series: Themes in Translation Studies, 20, 74-93.

handset or is it a loudspeaker?" [...] [T]hen I'll say, "If [...] it's a handset, would you mind keeping the questions short so that I can ask and they can answer?" (B5)

Aware as she is of the challenges to communication inherent to phone passing, through her briefing, B5 tries to influence the way the doctor proceeds with the consultation. In doing so, she challenges the doctor's authority to determine the course of the conversation singlehandedly. In addition, her request to "[keep] the questions short" is an attempt to control ways of speaking and protocols instead of placing the onus on her to use strategies such as note-taking to handle a sequence of questions, or longer turns. The participants differed in the way they handle longer chunks of discourse, some showing more awareness than others of the strategies needed in TI. B2 commented:

[T] he way I work over-the-phone is really different than when I do face-to-face interpreting, in the sense that often when the hospital [...] phones in the middle of the night, [...] what we tend to do, [...] I just [get] a piece of paper and a pen and the doctor will ask like five questions rather than just one and I write them down and then I speak to the patient and then I ask the questions, and I write down the answers and that makes it a bit easier.

Elsewhere, the same interpreter referred to the difficulty of giving a briefing at night when "[Y]ou pick up the phone and [...] you can't even remember what your name [is]" (B2). Both statements show little awareness of role and responsibility in the job accepted, calling into question the accountability of the interpreter and the hiring agency vis-à-vis clients.

\section{Responding to B2, B3 commented,}

It very often happens the way that number 2 explained. [...] [I]n real-life interpreting you would either do it simultaneously or consecutively and it would be much more precise. While in telephone interpreting, you paraphrase, because it's not possible to note down every single word, especially if the patient is a talkative one. [...] It's not possible to memorise [...] five long answers to five different questions. So, you remember [...] the core message. [...] [I]t changes the nature of interpreting [...] a lot just because it's done over the phone. (B3)

For B3, the strategy outlined by B2 is not particular to night-time interactions; it is characteristic of $\mathrm{TI}$ in general. Given that B3 has six years' experience of doing $\mathrm{TI}$ and, like B2, is one of the six participants who studied for and received the DPSI, it is surprising that she reported experiencing difficulties with both note-taking and memorising information. Previous studies show that, if performed competently, remote interpreting can enable the accurate and thorough transfer of meaning (De Boe, 2019; Hornberger et al., 1996).

The difficulties B3 mentions may indicate two things: either the DPSI does not assess these skills sufficiently or B3 is, for some reason, unable to transfer skills used in F2F to TI. Although we have no information about B3's training in $\mathrm{TI}$, we know that, at the time this article was written, TI was not part of the DPSI, and it is possible that she had received no or minimal training in TI from her employer. Whatever the reality is, a lack of awareness of one's own limitations to perform a task and hiring without appropriate screening of skills are serious problems requiring immediate attention. 
Angelelli, C. V., \& Ross, J. M. (2021). Contextual diversity in telephone interpreting: Voices from healthcare interpreters in Scotland. Linguistica Antverpiensia, New Series: Themes in Translation Studies, 20, 74-93.

\subsection{Work-life balance}

Although work-balance was not part of the original protocol, this topic emerged in both focusgroup discussions. We include it here because interpreters draw a connection between technology used and stress. We hypothesise that problems related to work-life balance are a consequence of poor hiring practices on the part of industry and also of interpreters' unsatisfactory awareness of their own limitations.

Only one participant reported employing technology at home to make her work more efficient and less stressful:

I only accept the calls when I'm at home. [...] I can just use my headset, which work[s] really well. [...] If I can hear clearly, then I feel very nice. [...] If I don't know a word or two, I can just easily Google very quickly and that I can't really have the luxury of doing when I'm doing face-to-face interpreting. [...] I feel much easier [sic] taking notes quickly on the computer than with a pen ... with a pen and paper, which is what I do in face-to-face. (A1)

As A1 is registered with a major international TI provider, she is likely to have a large volume of TI work, so working from home may be more financially viable for her than it is for interpreters who cannot rely on substantial call traffic. Also, because she works for this provider, she is subject to tighter protocols, including the obligation to use a landline. In contrast, the majority of the interpreters report having difficulty incorporating $\mathrm{TI}$ assignments into their private lives. B3 states:

When you do face-to-face interpreting, you're there, you do this, nothing else is going on. You do telephone interpreting, it's either the middle of the night or you're just preparing dinner for your family, and they call you [..]: "Oh, can you do this very short interpreting?" [...] I have children. They scream, running around you. You're trying to find a quiet spot. It's not always possible. (B3)

In response, B2 mentioned that this kind of situation is why she tends to avoid TI. She recognises that it is not professional to interpret when the family are around. B3 concurred but added that "Very often they will call you and they will have no one else". B2 emphasised that she would always inform the agency that she was at home together with her children, "so it may be noisy". In this case, the interpreter seems to be aware of what professional conduct entails, but she does not stand up to the agency's pressuring her to perform her duty under questionable or less than ideal conditions.

An unexpected finding, which we intend to pursue, was that five of the 12 participants mentioned occasions when they have performed TI from their cars. They gave various justifications for this: for example, because the car is a quiet refuge from screaming children or barking dogs at home (B2, B5, B7) or because they are driving between F2F appointments $(A 2, A 5)$. When interpreters interpret from a car, this can involve multiple risks, all of which threaten the quality of the interpreter's performance in addition to having potentially fatal consequences. If interpreters perform TI while driving, even if they are using the hands-free function of their car, it may not be possible to focus solely on the work - take notes, for example - and, last but not least, drive safely. This finding casts doubt not only on the attitudes 
Angelelli, C. V., \& Ross, J. M. (2021). Contextual diversity in telephone interpreting: Voices from healthcare interpreters in Scotland. Linguistica Antverpiensia, New Series: Themes in Translation Studies, 20, 74-93.

and perceptions of interpreting as a professional practice as expressed by some participants, but also on the TI providers' concern for the quality of their service.

\section{Discussion}

Using focus groups to study healthcare telephone interpreters working in an urban area of Scotland has afforded us an in-depth understanding of the contextual diversity which characterizes $\mathrm{TI}$, and also of the perceptions and beliefs $\mathrm{TI}$ interpreters hold about their own practice. In addition, it gives us a glimpse of who performs $\mathrm{TI}$ and the ways in which $\mathrm{Tl}$ is performed.

The participants' responses shed light on the impact that different communicative configurations and technologies have on interpreters' performance. This diversity has not been foregrounded enough before, as TI has often been treated as a monolithic construct, which clearly it is not (cf. Rosenberg, 2007; Ross, 2019; Spinolo, 2018). For example, the participants revealed how an interpreter's choice of telephone technology could affect the place of Tl-activity in their life. In the writings on TI that are not rooted in empirical research (e.g., Gracia-García, 2002; Mikkelson, 2003), TI is presented as a good option for people who need or wish to work from home. This recommendation, however, and the depictions of $\mathrm{Tl}$ in much of the scholarly literature, are at odds with the rather chaotic domestic scenes described by the focus groups in Thistleshire.

Turning to the technology used by clients, the focus-group discussions would appear to bear out Rosenberg's deconstruction (2007) of TI into different "communicative configurations". The healthcare provider and the patient are always in one location, either using a speakerphone or sharing a mobile phone or a conventional landline telephone. The participants' comments reported in section 4.1.2 testify to the distinct challenges of speakerphone interpreting and telephone passing respectively. Furthermore, one might hypothesise that the use of single-handset telephones in the medical settings served by our focus-group participants contributes to the distinct structure of the telephone-mediated conversations described in section 4.2. Presumably, end users prefer not to be constantly passing the phone back and forth, especially if their utterances are very short. This may be why healthcare providers using single-handset phones or mobiles are sometimes inclined to present multiple questions to the interpreter and leave them to elicit responses before rendering them using summarised versions (Wadensjö, 1998).

Interpreters display considerable diversity in the ways in which they cope with the same communicative configuration (e.g., during phone-passing, extensive note-taking versus requesting the healthcare provider to ask question by question), and also in the varying degrees of awareness of their own responsibility and role in the interaction. In addition, interpreters differ in their abilities to coordinate, manage and cope with typical ways of speaking to healthcare providers and clients. These results also shed light on the persistence of inadequate practice on the part of the private- and public-sector entities offering $\mathrm{TI}$ language provision.

All of the above raises the question why professional language provision in healthcare is so inconsistent when services such as $\mathrm{TI}$ are funded by the state and are essential to ensuring 
Angelelli, C. V., \& Ross, J. M. (2021). Contextual diversity in telephone interpreting: Voices from healthcare interpreters in Scotland. Linguistica Antverpiensia, New Series: Themes in Translation Studies, 20, 74-93.

equality under the law. In the United Kingdom, equality is protected by the UK's Equality and Diversity Act (2010) and similar UK-wide and Scottish legislation (see McKelvey, 2019). The answer, perhaps, lies in the fact that, in NHS Scotland, TI appears to be provided largely by the private sector. Therefore, the NHS is dependent on the quality of the interpreters employed by the company or companies who win the tenders and also on the testing and monitoring they carry out, which clearly varies. Each separate health board (e.g., NHS Lothian, NHS Greater Glasgow and Clyde) puts TI out to tender and works with the company or companies that win.

While education and/or training in TI was not purposely the focus of the discussions in our study, in a spontaneous discussion on training with the February focus group it emerged that only one of the participants who took the DPSI course had learned something about TI. Given that (1) currently $\mathrm{TI}$ is commonly used in Scotland and (2) formal education and/or training can have an effect on interpreters' practices, it would be important to research whether or how $\mathrm{Tl}$ is included or covered in conventional translation and interpreting programmes and to explore the reasons behind such inclusion or exclusion. It should be acknowledged that this problem is not unique to Scotland: Fernández-Pérez (2017) in Spain, Cheng (2015) in New Zealand and Wang (2018a, 2018b) in Australia have all called for more attention being given to $\mathrm{Tl}$ training in interpreting programmes.

The issue of pre- or in-service TI training was not part of our scope. Some contributions to the discussions and subsequent correspondence with participants, however, give the general impression that they received minimal training from the agencies for whom they worked. Some interpreters also responded that they did not see the need for specific training in $\mathrm{TI}$ anyway (e.g., A2). That said, research suggests that the scarcity of training for TI interpreters and the resultant unprofessional behaviours are not unique to Scotland. In Australia, for example, unprofessional practices have been attested to in the literature (Xu et al., 2020). In the Q\&A following an online seminar comparing $\mathrm{TI}$ and F2F, Hale acknowledged that not all people who perform TI today in Australia are trained professionals, and not all companies supply the same quantity and quality of guidance and training (Hale, 2021).

Given the key role that interpreters play in providing access to healthcare services, the findings in this study support the need for academia and industry to join forces (Angelone et al., 2020) with the intention of conducting comparative-experimental studies to ascertain (1) what kinds of problem coordinating and managing interpreting activities (Baraldi \& Gavioli, 2012) (whether working F2F or over the telephone) create for interpreters and (2) whether and, if so, how problems differ among professional and non-professional interpreters (Angelelli, 2020). This also leads one to consider the need for industry and academia to come together in Scotland (1) to examine the qualifications that the private or the public sector require from freelancers or employees to provide $\mathrm{TI}$ and (2) to scrutinise the pre- or in-service training offered by organisations in relation to coordinating and managing over-the-phone interpreting.

\section{Conclusion}

Through focus groups of healthcare interpreters who provide $\mathrm{TI}$ in Thistleshire we examined their perceptions of and beliefs on (1) the different technologies used by interpreters and 
Angelelli, C. V., \& Ross, J. M. (2021). Contextual diversity in telephone interpreting: Voices from healthcare interpreters in Scotland. Linguistica Antverpiensia, New Series: Themes in Translation Studies, 20, 74-93.

clients respectively and their impact on the service provided; and (2) their strategies and techniques when performing TI. In addition, by briefly exploring the issue of $\mathrm{TI}$ and work-life balance raised by the participants in both focus groups, we have been able to provide further evidence of the co-existence of professional and non-professional behaviours on the part of both providers and practitioners of TI. Our findings regarding the communicative configurations and strategies used by $\mathrm{TI}$ interpreters offer a degree of detail and complexity largely missing from existing empirical research on $\mathrm{Tl}$, in which the voices and perceptions of interpreters rarely take centre stage. Indeed, one contribution of this study is its deconstruction of the umbrella notion of $\mathrm{TI}$ that pervades much of the literature.

Judging from the participants' contributions, when this study was conducted, TI for NHS Thistleshire in Scotland mostly involved speakerphones, single-handset desktop telephones and mobile phones. The participants discussed how all of these technologies "complicate" interpreting and add stress to their work. Moreover, it appears that phone passing is blamed for interpreters' feeling pressured to translate larger chunks of discourse and to interpret patients' responses using summarised renditions (Wadensjö, 1998).

On this and other points, interestingly, the participants demonstrate a strong awareness of the part they play in facilitating communication as they cope with both the distinct challenges of $\mathrm{Tl}$ and the general challenges of interpreting. This does not mean, though, that the participants perceive and perform their work in identical ways; indeed, the experiences and opinions shared during the study are highly varied.

The diversity of telephone interpreters' behaviours therefore appears to result from a range of contextual variables that have not been accorded sufficient significance in the literature. These include the diverse types of technology and communicative configurations used while providing $\mathrm{Tl}$ and also the uneven level of skills, education and/or training in interpreting and the differing degrees of professional awareness reported by participants.

\subsection{Limitations of this study and call for further research}

Our results are derived from two focus groups with a total of 12 participants. We are aware of the limitations of this study. Our work is exploratory and our research design does not allow us to generalize our findings to any other areas of interpreting or to any other geographical context. We acknowledge, however, that some of our findings have already emerged in the practice of $\mathrm{TI}$ in other settings and parts of the world (e.g., police contexts: Angelelli, 2015; Monteoliva-García, 2017).

As is evident from the findings of this study, the communicative configurations discussed among the participants appear to influence the ways in which interpreters perform their jobs. Further research is required on the consequences of clients using a speakerphone or deploying a single-handset telephone and switching it between speakers, a practice which (COVID-19 has taught us) carries considerable risk of contagion. Insight into the everyday realities of TI would be gained from empirical data on interpreters' taking calls from a mobile phone, whether driving, sitting in a parked vehicle or located elsewhere. 
Angelelli, C. V., \& Ross, J. M. (2021). Contextual diversity in telephone interpreting: Voices from healthcare interpreters in Scotland. Linguistica Antverpiensia, New Series: Themes in Translation Studies, 20, 74-93.

The participants' widespread use of mobile phones might reveal information about the macrocontext in which $\mathrm{TI}$ takes place. As the literature review has indicated, public service interpreting and $\mathrm{TI}$ are relative newcomers to Scotland. Because $\mathrm{TI}$ services were late to develop there, it was arguably more difficult for professional interpreting norms to establish themselves in companies, institutions and society at large. This may explain some of the practices undertaken by interpreters. Detailed research into the policies, training and monitoring implemented by TI companies might shed light on why interpreters undertake these activities, revealing the extent to which unprofessional behaviour is tacitly or explicitly condoned by service providers.

This special issue has afforded us the opportunity to zoom in to a specific context, that is, TI in the healthcare sector in an urban region of Scotland. Doing so has led us to uncover layers of complexity in $\mathrm{TI}$ in its manifold communicative configurations. Through exploring the various levels of this situated practice, we have contributed to deconstructing $\mathrm{TI}$ as a monolithic construct. In addition, our work shows how little is known about the background of those performing the role of telephone interpreters in both the public and the private sectors in Scotland: about their qualifications, their performance at the point of entry, how their performance is assessed and/or nurtured. Little is known, too, about the entry requirements and the variety of hiring and working practices of agencies that provide TI. Most importantly, our exploratory work raises questions about the quality of service, its management and its provision. 
Angelelli, C. V., \& Ross, J. M. (2021). Contextual diversity in telephone interpreting: Voices from healthcare interpreters in Scotland. Linguistica Antverpiensia, New Series: Themes in Translation Studies, 20, 74-93.

\section{References}

Amato, A. A. M. (2018). Challenges and solutions: Some paradigmatic examples. In A. A. M. Amato, N. Spinolo, \& M. J. González Rodríguez (Eds.), Handbook of remote interpreting (pp. 79-101). University of Bologna. https://doi.org/10.6092/unibo/amsacta/5955

Amato, A. A. M., Spinolo, N., \& González Rodríguez, M. J. (Eds.). (2018). Handbook of remote interpreting. University of Bologna. https://doi.org/10.6092/unibo/amsacta/5955

Angelelli, C. V. (2004). Medical interpreting and cross-cultural communication. Cambridge University Press. https://doi.org/10.1017/CBO9780511486616

Angelelli, C. V. (2006). Validating professional standards and codes: Challenges and opportunities. Interpreting, 8(2), 175-193. https://doi.org/10.1075/intp.8.2.04ang

Angelelli, C. V. (2011). "Can you ask her about chronic illnesses, diabetes and all that?" In C. Alvstad, A. Hild, \& E. Tiselius (Eds.), Methods and strategies of process research: Integrative approaches in Translation Studies (pp. 231-246). John Benjamins. https://doi.org/10.1075/btl.94.17ang

Angelelli, C. V. (2015). Justice for all?: Issues faced by linguistic minorities and border patrol agents during interpreted arraignment interviews. MonTI, 7, 181-205. https://doi.org/10.6035/Mon TI.2015.7.7

Angelelli, C. V. (2020). Non-professional interpreting and translation (NPIT). In E. Angelone, M. Ehrensberger-Dow, \& G. Massey (Eds.), The Bloomsbury companion to language industry studies (pp. 115-138). Bloomsbury Academic. https://doi.org/10.5040/9781350024960.0010

Angelone, E., Ehrensberger-Dow, M., \& Massey, G. (Eds.). (2020). The Bloomsbury companion to language industry studies. Bloomsbury Academic. https://doi.org/10.5040/9781350024960

Azarmina, P., \& Wallace, P. (2005). Remote interpretation in medical encounters: A systematic review. Journal of Telemedicine and Telecare, 11(3), 140-145. https://doi.org/10.1258/13576330536 88679

Baraldi, C., \& Gavioli, L. (Eds.). (2012). Coordinating participation in dialogue interpreting. John Benjamins. https://doi.org/10.1075/btl.102

Böser, U. (2016). Interviews and focus groups. In C. V. Angelelli \& B. J. Baer (Eds.), Researching translation and interpreting (pp. 236-246). Routledge.

Braun, S. (2015). Remote interpreting. In H. Mikkelson \& R. Jourdenais (Eds.), The Routledge handbook of interpreting (pp. 352-367). Routledge. https://doi.org/10.4324/9781315745381

Castagnoli, S., \& Niemants, N. (2018). Corpora worth creating: A pilot study on telephone interpreting. In C. Bendazzoli, M. Russo, \& B. Defrancq (Eds.), Intralinea, Special Issue on New Findings in Corpus-based Interpreting Studies. http://www.intralinea.org/specials/article/corpora worth creating a pilot study on telephone interpreting

Cheng, Q. (2015). Examining the challenges for telephone interpreters in New Zealand [Unpublished master's thesis]. Auckland University of Technology.

De Boe, E. (2019). Remote healthcare interpreting: A methodology to investigate quality. Argentinian Journal of Applied Linguistics, 7(1), 58-78.

De Boe, E. (2020). Remote interpreting in healthcare: A comparative study on the influence of telephone and videolink use on the quality of interpreter-mediated communication [Unpublished doctoral dissertation]. University of Antwerp.

De Pedro Ricoy, R. (2010). Training public service interpreters in the UK: A fine balancing act. JoSTrans, 14. https://jostrans.org/issue14/art depedro.php

Edmunds, H. (1999). The focus group research handbook. NTC Business Books.

Equality and Diversity Act of 2010, UK Public General Acts2010 c. 15. (2010). https://www.legislation. gov.uk/ukpga/2010/15/contents

Fernández-Pérez, M. M. (2017). Interaction management skills in telephone interpreting. Revista Canaria de Estudios Ingleses, 75, 103-117. 
Angelelli, C. V., \& Ross, J. M. (2021). Contextual diversity in telephone interpreting: Voices from healthcare interpreters in Scotland. Linguistica Antverpiensia, New Series: Themes in Translation Studies, 20, 74-93.

Gany, F., Leng, J., Shapiro, E., Abramson, D., Motola, I., Shield, D. C., \& Changrani, J. (2007). Patient satisfaction with different interpreting methods: A randomized controlled trial. Journal of General Internal Medicine, 22, 312-318. https://doi.org/10.1007/s11606-007-0360-8

Goebert, B., \& Rosenthal, H. M. (2001). Beyond listening: Learning the secret language of focus groups. Wiley.

Gracia-García, R. A. (2002). Telephone interpreting: A review of pros and cons. In B. Scott (Ed.), Proceedings of the 43rd annual conference (pp. 195-216). American Translators Association.

Hale, S. (2021, March 25). Remote vs face-to-face interpreting: Does it make a difference in interpreter performance? [Online research seminar]. University of Manchester, Centre for Translation and Intercultural Studies.

Hild, A. (2014). The role of self-regulatory processes in the development of interpreting expertise. Translation and Interpreting Studies, 9(1), 128-149. https://doi.org/10.1075/tis.9.1.07hil

Hornberger, J. C., Gibson, C. D., Wood, W., Dequeldre, C., Corso, I., Palla, B., \& Bloch, D. A. (1996). Eliminating language barriers for non-English-speaking patients. Medical Care, 34(8), 845-856. https://doi.org/10.1097/00005650-199608000-00011

Hornberger, J. C., Itakura, H., \& Wilson, S. R. (1997). Bridging language and cultural barriers between physicians and patients. Public Health Reports, 112(5), 410-417.

Houria, A. A. (2021). Onsite interpreting versus remote interpreting in the COVID 19 world. Review: Applied Linguistics, 5(9), 339-344.

Joseph, C., Garruba, M., \& Melder, A. (2018). Patient satisfaction of telephone or video interpreter services compared with in-person services: A systematic review. Australian Health Review, 42(2), 168-177. https://doi.org/10.1071/AH16195

Ko, L. (2006). The need for long-term empirical studies in remote interpreting research: a case study of telephone interpreting. Linguistica Antverpiensia, New Series: Themes in Translation Studies, 5, 325-338.

Lee, J. (2007). Telephone interpreting - seen from the interpreters' perspective. Interpreting, 9(2), 231-252. https://doi.org/10.1075/intp.9.2.05lee

Lion, K. C., Ebel, B. E., Rafton, S., Zhou, C., Hencz, P., \& Mangione-Smith, R. (2015). Evaluation of a quality improvement intervention to increase use of telephonic interpretation. Pediatrics, 135(3), 709-716. https://doi.org/10.1542/peds.2014-2024

Locatis, C., Williamson, D., Gould-Kabler, C., Zone-Smith, L., Detzler, I., Robertson, J., Maisiak, R., \& Ackerman, M. (2010). Comparing in-person, video, and telephonic medical interpretation. Journal of General Internal Medicine, 25(4), 345-350. https://doi.org/10.1007/s11606-009-12 $\underline{36-x}$

McKelvey, R. (2019). Language provision in Scottish public services: Inclusion in policy and in practice [Unpublished doctoral dissertation]. University of Edinburgh.

Mikkelson, H. (2003). Telephone interpreting: Boon or bane? In L. P. González (Ed.), Speaking in tongues: Language across contexts and users (pp. 251-269). University of Valencia.

Mitchell, S. (2018, February 23). Integrated impact assessment. https://www.nhslothian.scot/Your Rights/EqualityDiversity/RapidlmpactAssessments/Interpretation\%20and\%20Translation\%20 Service230218.pdf

Monteoliva-García, E. (2017). The collaborative construction of the stand-by mode of interpreting in police interviews with suspects [Unpublished doctoral dissertation]. Heriot-Watt University.

Monteoliva-García, E. (2020). Interpreting or other forms of language support? Experiences and decision-making among response and community police officers in Scotland. Translation \& Interpreting, 12(1), 37-54. https://doi.org/10.12807/ti.112201.2020.a03

Morgan, D. L. (1997). Focus groups as qualitative research (2nd ed.). Sage. https://doi.org/10.4135/97 81412984287

Nimdzi Research. (2020, April 15). Interpreting in times of COVID-19. https://www.nimdzi.com/inter preting-in-times-of-covid-19/ 
Angelelli, C. V., \& Ross, J. M. (2021). Contextual diversity in telephone interpreting: Voices from healthcare interpreters in Scotland. Linguistica Antverpiensia, New Series: Themes in Translation Studies, 20, 74-93.

Oviatt, S. L., \& Cohen, P. R. (1992). Spoken language in interpreted telephone dialogues. Computer Speech and Language, 6(3), 277-302. https://doi.org/10.1016/0885-2308(92)90021-U

Ozolins, U. (2011). Telephone interpreting: Understanding practice and identifying research needs. Translation \& Interpreting, 3(1), 33-47.

Perez, I. A., \& Wilson, C. W. L. (2006). Translating, interpreting and communication support: A review of provision in public services in Scotland. Scottish Executive Social Research. https://dpsion line.co.uk/wp-content/uploads/2020/08/Translating-Interpreting-and-Communication-Sup port -a-Review-of-Provision-in-Public-Services-in-Scotland.pdf

Price, E. L., Pérez-Stable, E. J., Nickleach, D., López, M., \& Karliner, L. S. (2012). Interpreter perspectives of in-person, telephonic, and videoconferencing medical interpretation in clinical encounters. Patient Education \& Counselling, 87(2), 226-232. https://doi.org/10.1016/i.pec.2011.08.006

René de Cotret, F., Beaudoin-Julien, A.-A., \& Leanza, Y. (2020). Implementing and managing remote public service interpreting in response to COVID-19 and other challenges of globalization. Meta, 65(3), 618-642. https://doi.org/10.7202/1077406ar

Rosenberg, B. A. (2007). A data driven analysis of telephone interpreting. In C. Wadensjö, B. EnglundDimitrova, \& A.-L. Nilsson (Eds.), The Critical Link 4: Professionalisation of interpreting in the community (pp. 65-78). John Benjamins.

Ross, J. M. (2019, November 21-22). "Please pass the phone, I'll ask...": Communicative configuration and telephone interpreting in Turkey [Paper presentation]. InDialog3: Interpreter practice, research and training: The impact of context, Antwerp, Belgium.

Shaw, S., Grbić, N., \& Franklin, K. (2004). Applying language skills to interpretation: Student perspectives from signed and spoken language programs. Interpreting, 6(1), 69-100. https:// doi.org/10.1075/intp.6.1.06sha

Spinolo, N. (2018). Traditional face-to-face vs telephone-mediated communication - with an interpreter. In A. Amato, N. Spinolo, \& M. J. González Rodríguez (Eds.), Handbook of remote interpreting (pp. 72-78). Erasmus+/European Union. https://doi.org/10.6092/ unibo/amsacta/5955

Spinolo, N., Bertozzi, M., \& Russo, M. (2018). Basic tenets and features characterising telephone- and video-based remote communication in dialogue interpreting. In A. Amato, N. Spinolo, \& M. J. González Rodríguez (Eds.), Handbook of remote interpreting (pp. 12-25).. https://doi.org/10.6092/unibo/amsacta/5955

Wadensjö, C. (1998). Interpreting as interaction. Longman.

Wadensjö, C. (1999). Telephone interpreting and the synchronization of talk in social interaction. The Translator, 5(2), 247-264. https://doi.org/10.1080/13556509.1999.10799043

Wang, J. (2018a). "Telephone interpreting should be used only as a last resort": Interpreters' perceptions of the suitability, renumeration and quality of telephone interpreting. Perspectives, 26(1), 100-116. https://doi.org/10.1080/0907676X.2017.1321025

Wang, J. (2018b). "It keeps me on my toes": Interpreters' perceptions of challenges in telephone interpreting and their coping strategies. Target, 30(3), 439-473. https://doi.org/10.1075/tar get.17012.wan

Xu, H., Hale, S., \& Stern, L. (2020). Telephone interpreting in lawyer-client interviews: An observational study. Translation \& Interpreting, 12(1), 18-36. https://doi.org/10.12807/ti.112201.2020.a02 
Angelelli, C. V., \& Ross, J. M. (2021). Contextual diversity in telephone interpreting: Voices from healthcare interpreters in Scotland. Linguistica Antverpiensia, New Series: Themes in Translation Studies, 20, 74-93.

\section{APPENDIX A: Semi-structured protocol for the focus groups}

Telephone technologies \& communicative configurations

- When you're doing telephone interpreting, what kind of telephone do you use?

- What kind of telephone do parties you interpret for use?

- Does the technology used make any difference? Please comment.

- Does the technology used affect the way you interpret? If so, how?

Interpreters' strategies and procedures in $\mathrm{TI}$

- When you're interpreting over the telephone, do you think the ways you manage communication and interpret are different from how they are when you're working face-to-face? If so, how?

- Do you think the setting (healthcare, police, etc.) makes any difference?

O Is there anything about the healthcare setting that makes the way you interpret over the telephone different from how you interpret in other settings? If so, please explain.

○ Do you think the specific type of medical setting (GP, emergency, in-patient, etc.) or condition (birth, end-of-life, major/minor illness, etc.) makes a difference too?

The affective dimension

- Does the fact that you're interpreting over the telephone make you feel any different when you're serving a healthcare setting? How?

- Do you think it's generally more stressful to interpret over the telephone than faceto-face?

- As you have gained more experience, have you noticed a change in your emotions while doing telephone interpreting?

The lack of visual contact

- Many practitioners and researchers have said that the main disadvantage of telephone interpreting for healthcare settings is the lack of visual contact between the interpreter, the healthcare provider and the client. What are your thoughts?

- Is it important for the interpreter to see the other parties? If so, why?

- Might there be advantages in the interpreter not seeing the other parties? Please discuss.

- Do you think there are ways in which a telephone interpreter can overcome the lack of visual contact? What are they?

- In your practice, have you noticed your ability to deal with the lack of visual contact change with time? If so, how? 
Angelelli, C. V., \& Ross, J. M. (2021). Contextual diversity in telephone interpreting: Voices from healthcare interpreters in Scotland. Linguistica Antverpiensia, New Series: Themes in Translation Studies, 20, 74-93.

1 Thistleshire is the fictitious pseudonym we have chosen to stand for the region of Scotland where we conducted our focus groups. NHS (National Health Service) Thistleshire is the public body responsible for providing healthcare services in that region. 